\title{
Bilateral Orthotopic Ureteroceles
}

\section{Abstract:}

Background: Developmental abnormalities of the upper urinary tract including duplex system, ectopic ureter and ureterocele are frequently observed. Clinical presentations are variable and continue to challenge clinical management. Case Report: We are presenting a case of bilateral orthotopic; simple, ureterocele in an adult male with no congenital malformations of the renal or collecting system. The patient was diagnosed provisionally with bilateral ureterocele using abdominal ultrasonography in primary health care facility and referred to our urology clinic for further assessment and management. Conclusion: Bilateral intravesical ureterocele in an adult male with normal upper tract development is a rare clinical presentation. While, intervention is necessary in infants and young children, non-operative approach can achieve stable clinical scenario, maintaining both normal renal function and optimal quality of life in adults.

Key words: Kidney, Ureter, Ureteral Obstruction, Ureterocele, Urology.

\section{Introduction}

Ureterocele is a congenital defect affecting one or both ureters which is frequently associated with other abnormalities of the urinary system. Several new studies provide insights into the normal processes of ureteric maturation, and highlight possible causes of obstruction, reflux and ureteral abnormalities [1]. Ureterocele may be either intravesical which is entirely within the bladder or ectopic; in which some portion of the ureterocele is situated at the bladder neck or urethra. Clinical findings are variable. Currently, many cases are antenatally diagnosed by ultrasound. Patients commonly present with urinary tract infection, on the other hand, mild forms of ureterocele are found occasionally in adults examined for unrelated reasons [2]. Treatment must be individualized. Transurethral incision is recognized as the definitive procedure in many instances, particularly in patients with intravesical ureteroceles and especially in neonates.

\section{Case Report}

A 59 years old, Omani male patient was referred to our urology department in Sheikh Khalifa hospital in United Arab Emirates from primary health care facility with bilateral intravesical ureterocele, bilateral mild to moderate hydroureteronephrosis diagnosed by abdominal ultrasound [Fig. 1,2].

Corresponding Author: Dr. Mohammed R. Aljumaili

Email: maljumayli@yahoo.com

Received: April 21, 2016 | Accepted: July 13, 2016 | Published Online: September 15, 2016

This is an Open Access article distributed under the terms of the Creative Commons Attribution License (creativecommons.org/licenses/by/3.0)

Conflict of interest: None declared | Source of funding: Nil | DOI: http://dx.doi.org/10.17659/01.2016.0106 
Patient presented to his family physician complaining of acute recurrent epigastric pain or discomfort of 2 weeks duration, his primary clinical assessment and abdominal ultrasonography reported. Pain was the main and only complain and was localized to the epigastric region, not radiating to other regions or back. He denies any history of significant fever, dysuria, hematuria and lower urinary tract symptoms. He claims normal bowel habits, however he denies dyspepsia, constipation and indigestion, his systemic review was unremarkable, patient denies diabetes mellitus and hypertension, he was not commenced on regular medications apart from paracetamol for simple headache His family history was negative for similar condition or other congenital abnormalities, he is married for 40 years and he had 5 children, he is non-smoker and denied alcohol consumption.

Patient was tall and relatively thin with BMI 18, normal temperature, no pallor and no jaundice. Physical examination was unremarkable, liver; spleen and his bladder were not palpable. Preliminary complete blood count, biochemistry including renal function and urine test were within normal range. The previous ultrasonographic anatomical and structural findings of bilateral orthotopic ureteroceles, non-obstructing floating stones within the left ureterocele and bilateral mild to moderate hydroureteronephrosis were confirmed by contrast enhanced CT (computed tomography) scan [Fig.3-5]. Vesicoureteric reflux was excluded by VCUG (voiding cystourethrography) [Fig.6, 7] and Tc99-m DTPA renal study reveals normal functioning kidneys with outflow stasis.

The clinical condition and treatment options were reviewed and discussed with the patient who refused to proceed with diagnostic cystoscopy and preferred to carry on conservative management and active surveillance with regular follow up visits every 4 months. Patient was subjected to full medical history and physical examination, routine

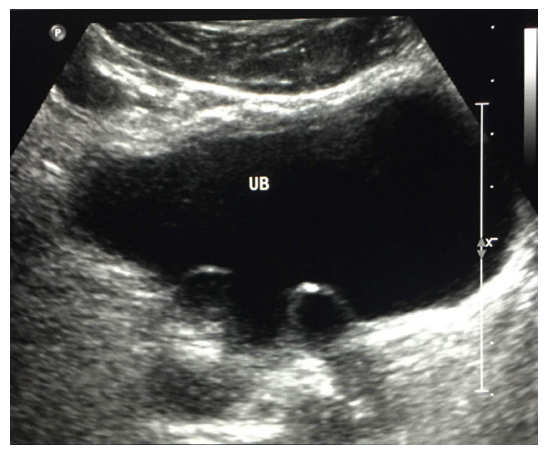

Fig.1: Sonography of the urinary bladder, revealed a saccular outpouching of the distal end of both ureters, into the distended urinary bladder.

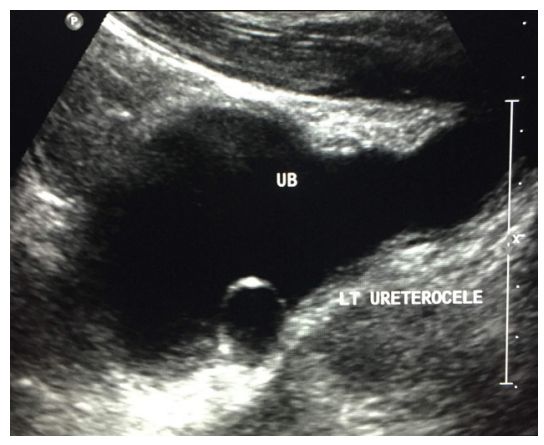

Fig.2: Sonography of the urinary bladder in longitudinal section shows the ureterocele at the site of insertion of the normal anatomical site of ureter.

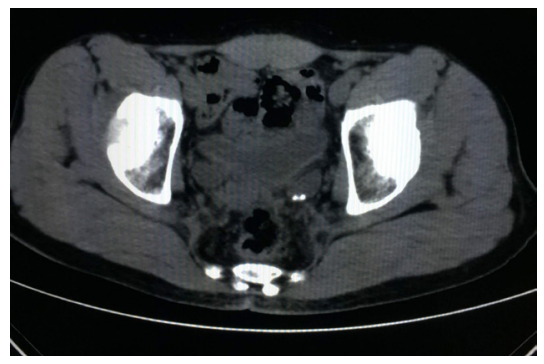

Fig.3: Pre-contrast CT scan at the level of the bladder image revealed bilateral hydroureter with two stones seen floating in the left distal ureter. Also there is left renal small stone (seen on renal sections). 


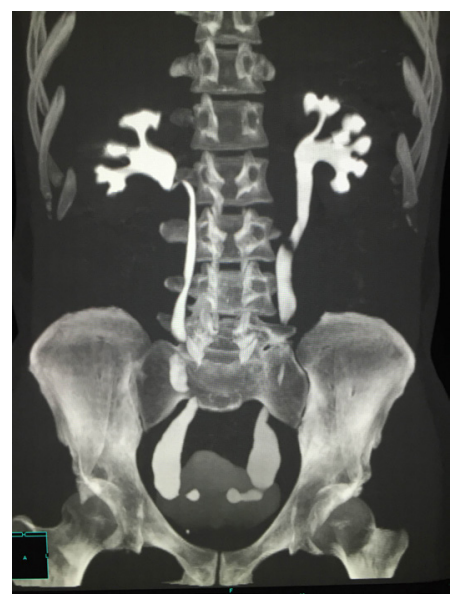

Fig.4: CT urogram revealed bilateral hydroureteronephrosis, bilateral saccular collection of contrast with a halo of lucency surrounding it (Cobra head sign) characteristic of a ureterocele (bilateral orthotopic ureteroceles) At the site of insertion of the normal anatomical site of ureters.

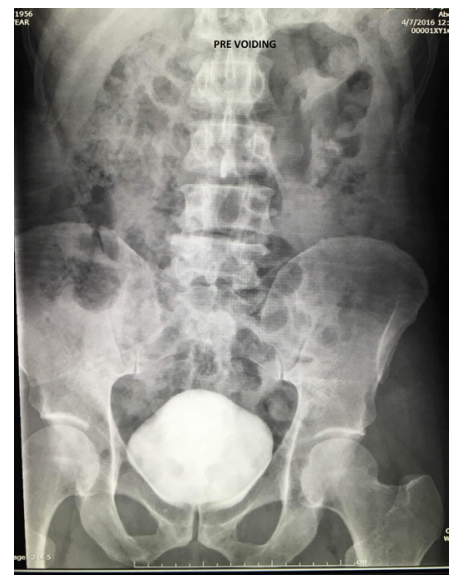

Fig.6: Voiding cystourethrogram (VCUG) pre voiding study shows no reflux.

blood and urine tests. Structural abnormalities were best followed by ultrasonography which was done in each visit, in addition to contrast enhanced CT scan, renal scan studies were done to monitor his renal function at one year. After four consecutive

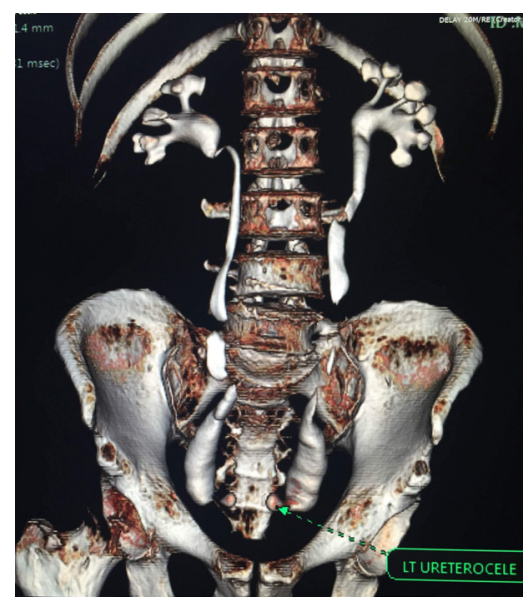

Fig.5: CT with 3D reconstruction show bilateral hydroureteronephrosis \& ureteroceles.

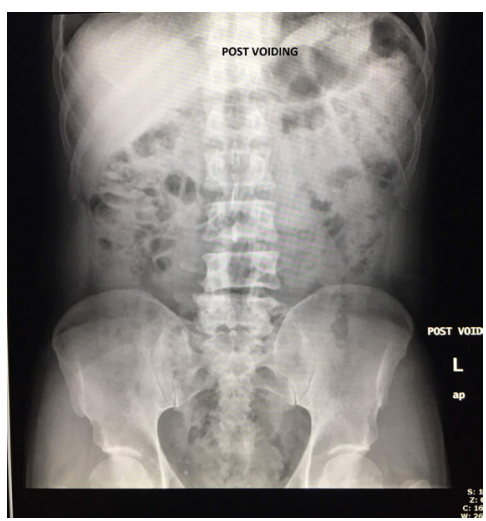

Fig.7: Voiding cystourethrogram (VCUG) post voiding study shows no reflux.

follow up visits, no breakthrough urinary tract infections was recorded and no antibiotics were prescribed.

Patient was informed about the risk of urinary tract infection and vesicoureteric junction obstruction and the need for urgent intervention in either case. The clinical and biochemical assessment were within normal. The previous radiological findings were stable and no further abnormalities detected after one and a half year follow up. 


\section{Discussion}

Ureterocele is a saccular dilation of the distal portion of the ureter which reflects defective ureteral maturation. The classic explanation for the development of ureterocele is failure of rupture of a membrane at the ureteral orifice (Chwalle membrane). While others attribute it to incomplete canalization of the ureteral bud leading to an obstruction and expansion prior to its absorption into the urogenital sinus $[1,2]$. Ureterocele is 4-7 times more frequent in female than in male patients; the overall incidence in autopsies is around 1 in 4,000 children. Around $80 \%$ is associated with the upper pole ureter in duplicated systems and $20 \%$ in single systems. About $10 \%$ of ureteroceles are bilateral [3]. Bilateral, single system ureterocele in male patient as presented in the paper is a rare clinical scenario.

Ureterocele may be either intravesical which is entirely within the bladder, this would include a "simple" ureterocele associated most often with single ureters that may be seen in the adult with minimal dilation and mild to no hydronephrosis or ectopic; in which some portion of the ureterocele is situated permanently at the bladder neck or urethra and nearly always involve the upper pole of duplex system. Ectopic ureteroceles are more frequently diagnosed than intravesical ureterocele. Although patient refused diagnostic cystoscopy, radiological workup confirms the intravesical location of ureterocele in our patient which is the rare variant $[3,4]$.

Clinical findings are variable. Currently, many cases are antenatally diagnosed by ultrasound. Mild forms of ureterocele are found occasionally in adults examined for unrelated reasons as described for our case [5]. Urinary tract infection is a common presentation, ureterocele may prolapse through the female urethra [6] or large unilateral ureterocele may displace the opposite orifice resulting in reflux, bladder outlet obstruction or incontinence. Urolithiasis and renal failure are major complications secondary to urinary stasis. Hydroureteronephrosis and dysplasia of the upper pole of the kidney may be found in association with ureterocele $[7,8]$.

The presence of stones in the left ureterocele is a risk factor for the future development of vesicoureteric junction obstruction and laser lithotripsy was offered to manage the stone endo-urologically. Excretory urography is usually diagnostic. However, at present ultrasonography has replaced the excretory urogram for the diagnosis of ureteroceles [6]. It is mandatory to rule out reflux to the lower pole and or contralateral ureter using voiding cystourethrography which should always be part of the assessment. Renal scanning is helpful for estimating renal function, both were done and reported as normal $[9,10]$. Ultrasonography, radionuclide imaging, VCUG, MR urography, high-resolution MRI, and cystoscopy are all helpful diagnostic tools to assess function, to detect reflux and rule out ipsilateral compression of the lower pole and urethral obstruction [1 1]. In some cases, the large ectopic ureter presses against the bladder and can look like a pseudo-ureterocele [12].

With regard to management and at time of presentation, prophylactic antibiotic treatment is indicated until reflux is ruled out. The choice of an intervention depends on certain criteria: clinical presentation; patient's age; renal function; type of ureterocele; presence of reflux or obstruction of both ureters; presence of bladder neck obstruction; and parents' and surgeon's preferences $[13,14]$. Asymptomatic patients can be managed conservatively provided bladder outlet obstruction, and severe hydroureteronephrosis or high-grade reflux had been ruled out [15]. 
Transurethral incision is effective procedure for many cases and if it is successful and there is no reflux, the patient is followed-up conservatively. On the other hand, most of the children with an extravesical ureterocele (50\%-80\%) need a secondary procedure, compared with only $18 \%$ of those with an intravesical ureterocele $[15,16]$. Secondary surgery is indicated upon failure of transurethral incision, persistent reflux and the presence of obstruction of ureters, and/or bladder neck or retained ureterocele. Surgery may vary from upper pole nephrectomy to complete unilateral lower urinary tract reconstruction [16]. In an ectopic ureterocele with severe hydroureteronephrosis and without reflux, the primary upper tract approach without endoscopic decompression (partial upperpole nephroureterectomy, ureterostomy and upper-pole ureterectomy) gives upto an $80 \%$ chance of being the definitive treatment $[16,17]$. While transurethral incision is recognized as the definitive procedure in many instances, particularly in neonates with intravesical ureteroceles. A non-operative conservative approach may be implemented in non-complicated adult cases [15]. Although cystoscopy was not done in our case, the asymptomatic presentation and stable renal function were the main criteria that warrant nonsurgical approach.

The management of ureterocele is problematic with a choice between a non-operative approaches, endoscopic decompression, ureteral reimplantation, partial nephrectomy, or complete primary reconstruction [13-17].

\section{Conclusion}

Bilateral intravesical, simple ureterocele in an adult male with normal upper tract development is a rare clinical presentation. In general, patients presented with ureterocele may exhibit variety of clinical presentations. Proper clinical and radiological assessments are mandatory to facilitate decision making, optimizing management goals and avoiding consequences. The choices range from conservative management and extended follow up on one hand and incision, excision of ureterocele or heminephrectomy, ureterectomy with or without vesical reconstruction and ureteral reimplantation on the other hand. Intervention is necessary in young children, however; non-operative management can achieve stable clinical scenario, maintaining both normal renal function and optimal quality of life in adults.

\section{References}

1. Chwalla R. The process of formation of cystic dilatation of the vesical end of the ureter and of diverticula at the ureteral ostium. Urol Cutan Ren. 1927;31:499.

2. Mendelsohn C. Using mouse models to understand normal and abnormal urogenital tract development. Organogenesis. 2009;5(1):306314.

3. Glassberg KI, Braren V, Duckett JW, Jacobs $E C$, King LR, Lebowitz RL, et al. Terminology for duplex systems, ectopic ureters and ureteroceles. J Urol. 1984;132(6): 11 153-1154.

4. Snyder HM, Johnston JH. Orthotopic ureteroceles in children. J Urol. 1978;1 19(4):543-546.

5. Upadhyay J, Bolduc S, Braga L, Farhat W, Bägli DJ, McLorie GA, et al. Impact of prenatal diagnosis on the morbidity associated with ureterocele management management. J Urol. $2002 ; 167(6): 2560-2565$.

6. Ahmed S. Prolapsed single system ureterocele in a girl. J Urol. 1984;132(6):1 180.

7. Barry A. Kogan MD. Disorders of the ureter and ureteropelvic junction. In: Emil A. Tanago, Jack W, editors. Simth's General Urology. $17^{\text {th }}$ edition. McGraw Hill, Newyork: 2008.

8. Gloor JM, Ogburn P, Matsumoto J. Prenatally diagnosed ureterocele presenting as fetal bladder outlet obstruction. J Perinatol. 1996; 16(4):285-287. 
9. Geringer AM, Berdon WE, Seldin DW, Hensle TW. The diagnostic approach to ectopic ureterocele and the renal duplication complex. J Urol. 1983; 1 29(3):539-542.

10. Connolly LP, Connolly SA, Drubach LA, Zurakowski D, Ted Treves S. Ectopic ureteroceles in infants with prenatal hydronephrosis: use of renal cortical scintigraphy. Clin Nucl Med. 2002;27(3):169-175.

11. Ehammer T, Riccabona M, Maier E. High resolution $M R$ for evaluation of lower urogenital tract malformations in infants and children: feasibility and preliminary experiences. Eur J Radiol. 2011 ;78(3):388-393.

12. Sumfest JM, Burns MW, Mitchell ME. Pseudoureterocele: potential for misdiagnosis of an ectopic ureter as aureterocele. $\mathrm{Br} J$ Urol. $1995 ; 75(3): 401-405$.
13. Mariyappa B, Barker A, Samnakay N, Khosa J. Management of duplex-system ureterocele. J Paediatr Child Health. 2014;50(2):96-99.

14. Coplen DE. Management of the neonatal ureterocele. Curr Urol Rep. 2001;2(2):102105.

15. Han MY, Gibbons MD, Belman AB, Pohl HG, Majd $M$, Rushton HG. Indications for nonoperative management of ureteroceles. J Urol. 2005;174(4 Pt 2):1652-5; discussion 1655-6.

16. Pfister C, Ravasse P, Barret E, Petit T, Mitrofanoff P. The value of endoscopic treatment for ureteroceles during the neonatal period. J Urol. 1998; 159(3):1006-1009.

17. Byun E, Merguerian PA. A meta-analysis of surgical practice patterns in the endoscopic management of ureteroceles. J Urol. 2006. 176(4 Pt 2): pp. 1871-7; discussion 1877. 